\title{
Modular Synthesis of Functionalized Butenolides by Oxidative Furan Fragmentation
}

\author{
Jiajing Bao, $\uparrow$ Hailong Tian, $\uparrow$ Peicheng Yang, Jiachen Deng and Jinghan Gui* \\ CAS Key Laboratory of Synthetic Chemistry of Natural Substances, Center for Excellence in Molecular Synthesis, Shanghai \\ Institute of Organic Chemistry, University of Chinese Academy of Sciences, Chinese Academy of Sciences, 345 Lingling \\ Road, Shanghai 200032, China
}

\begin{abstract}
The development of new chemical transformations to simplify the synthesis of valuable building blocks is a challenging task in organic chemistry and has been the focus of considerable research effort. From a synthetic perspective, it would be ideal if the natural reactivities of feedstock chemicals could be diverted to the production of high value-added compounds which are otherwise tedious to prepare. Here we report a chemical transformation that enables facile and modular synthesis of synthetically challenging yet biologically important functionalized butenolides from easily accessible furans. Specifically, Diels-Alder reactions between furans and singlet oxygen generate versatile hydroperoxide intermediates, which undergo iron(II)-mediated radical fragmentation in the presence of $\mathrm{Cu}(\mathrm{OAc})_{2}$ or various radical trapping reagents to afford butenolides bearing a wide variety of appended remote functional groups, including olefins, halides, azides and aldehydes. The practical utility of this transformation is demonstrated by easy diversification of the products by means of cross-coupling reactions and, most importantly, by its ability to simplify the syntheses of known building blocks of eight biologically active natural products.
\end{abstract}

\section{— INTRODUCTION}

Butenolides are a class of five-membered-ring unsaturated lactones that are present in a wide variety of compounds such as food additives, agrochemicals, pharmaceuticals and biologically active natural products. Examples include vitamin $\mathrm{C}$ (ascorbic acid, 1, Figure 1a), which is an essential nutrient found in various foods and is used as a dietary supplement to prevent and treat scurvy; 3-methyl-2 $H$-furo[2,3-c]pyran-2-one (2), which is isolated from plant-derived smoke and promotes germination of the seeds of agricultural weeds $;^{1}$ and clavilactone $\mathrm{A}(\mathbf{3})^{2}$ and pyranicin $(4),{ }^{3}$ natural products that exhibit antifungal, antibacterial, pesticidal, immunosuppressive, and antitumor activities, among others. Compounds $\mathbf{3}$ and $\mathbf{4}$ could potentially be accessed convergently via a fragment-coupling strategy involving butenolides with appended remote functional groups as key coupling partners. The various conventional approaches for constructing butenolides have been reviewed ${ }^{4}$ and include ring-closing metathesis of unsaturated esters,,${ }^{3 \mathrm{f}}$ intermolecular alkylation of $\alpha$-sulfenyl $\gamma$-lactones, ${ }^{5}$ intermolecular Aldol reactions ${ }^{6}$ and $\mathrm{Pd}$-catalyzed carbonylation of vinyl iodides. ${ }^{7}$ However, these approaches generally suffer from two limitations: they require lengthy and tedious manipulations, and they lack modularity: that is, each structural motif is synthesized by a completely different synthetic strategy. Therefore, the development of a concise and modular approach to functionalized butenolides from simple and readily available starting materials would be highly desirable.

One powerful strategy for rapidly generating molecular complexity is carbon-carbon $(\mathrm{C}-\mathrm{C})$ bond fragmentation. ${ }^{8}$ This strategy has found numerous applications in natural product synthesis $^{9}$ and materials science ${ }^{10}$ and has drawn considerable attention from synthetic chemists over the years. ${ }^{11}$ Classic examples include the Grob ${ }^{12}$ and Eschenmoser-Tanabe ${ }^{13}$ fragmentations, dating back to the 1950 s, for the expedient synthesis of alkenes and alkynes (Figure 1b). In addition to ionic fragmentation, ${ }^{14}$ radical fragmentation is also widely used. ${ }^{15}$ Examples pertinent to this study include the seminal work on iron-mediated decomposition reactions of hydroperoxides reported by Kochi, ${ }^{16}$ Schreiber, ${ }^{17}$ and Newhouse. ${ }^{18}$ In these reactions, the $\mathrm{O}-\mathrm{O}$ bond of the hydroperoxide is cleaved in the presence of an iron(II) salt to give an alkoxy radical, which undergoes $\beta$-fragmentation to generate an alkyl radical. Subsequent oxidation of the alkyl radical by a copper(II) salt furnishes the alkene product. Although this strategy is exceptionally powerful for oxidative cleavage of ketones, removal of an isopropenyl group, ${ }^{11 c, 19}$ and macrolide synthesis, ${ }^{20}$ it has rarely been used for selective fragmentation of feedstock chemicals (such as furans) to provide efficient, direct access to high-value-added compounds.

Because furans are inexpensive, readily available, and highly reactive, they are versatile synthons and have frequently been used to access a wide array of valuable building blocks. ${ }^{21}$ Typical transformations of furans include Diels-Alder reactions to afford butenolides and 1,4-diketones, Achmatowicz reactions to furnish pyranones and pyridones, and Mukaiyama Aldol reactions to form butenolides (Figure 1c). Despite the frequent application of these classic transformations in natural product synthesis and medicinal chemistry, the use of furans to rapidly generate molecular complexity via $\mathrm{C}-\mathrm{C}$ bond fragmentation has rarely been reported..$^{22}$ Given the easy accessibility of furans, the development of a method for oxidizing the furan ring while concurrently cleaving the adjacent $\mathrm{C}-\mathrm{C}$ bond to generate functionalized butenolides would be highly appealing (Figure 1c). We speculated that an endoperoxide produced by a Diels-Alder reaction between a furan and singlet oxygen ${ }^{23}$ might form a hydroperoxide in $\mathrm{MeOH}$, which could then decompose in the presence of an iron(II) species to give a functionalized butenolide via radical fragmentation. The net outcome of this process would be the conversion of furans to synthetically challenging 
a Selected important molecules with butenolides

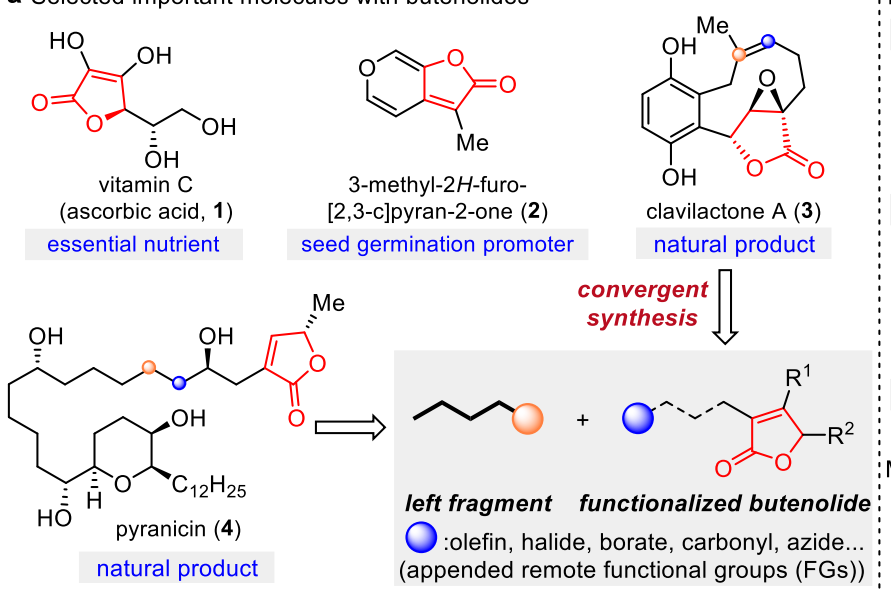

b Classic examples of bond fragmentations in organic synthesis Grob, 1955 Kochi, 1961

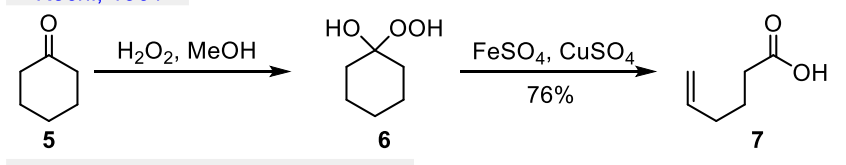

Schreiber, 1980; Newhouse, 2016

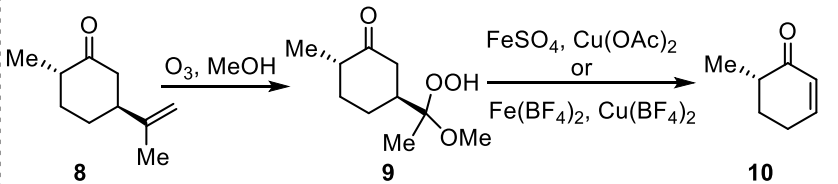

C Traditional transformations of furans and new development
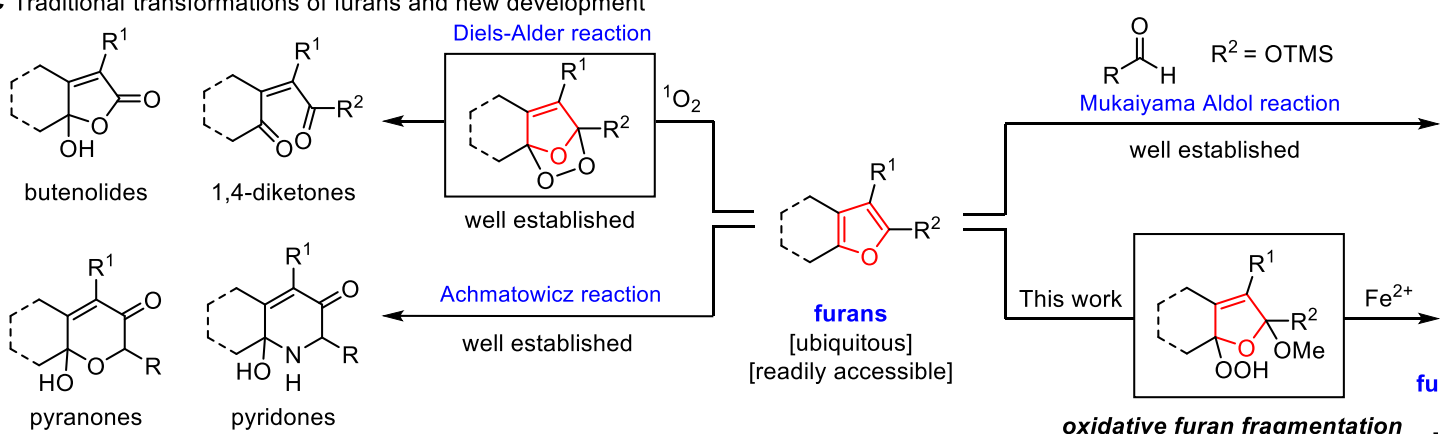

oxidative furan fragmentation

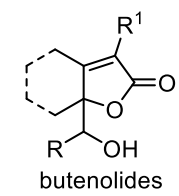

d Synthesis simplification enabled by this work

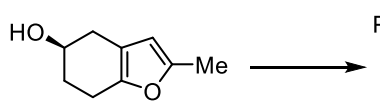

11
PMBO

12<smiles>[R]OC(C/C=C/I)CC1=CC([M])OC1=O</smiles>

$\mathrm{R}=$ MOM (13); TBS (14)
(B)

this work vs previous approach: 5 steps vs 9 steps

16

15

6 steps vs 10 steps 6 steps vs 12 steps
- one furan, five butenolides

- modular synthesis

- diverse remote FGs

- synthesis simplification

Figure 1. Overview of butenolides, bond-fragmentation strategies, and transformations of furans.

yet biologically important butenolides simply by using singlet oxygen and an inexpensive iron(II) salt. Herein we disclose the development of just such a process: specifically, we report that oxidative fragmentation of furans provides rapid, modular access to functionalized butenolides bearing a broad range of appended remote functional groups, including olefins, halides, azides, and aldehydes. Furthermore, we show that these remote functional groups can undergo various bond-forming reactions (Scheme 1), significantly expanding the chemical space of accessible butenolides. Most importantly, we demonstrate the power of our strategy by using it to simplify and shorten the syntheses of building blocks of eight biologically important natural products (Scheme 2). Examples include butenolides 12-16, which bear diverse remote functional groups and were concisely prepared in a modular fashion from a single starting material (furan 11, Figure 1d).

\section{- RESULTS AND DISCUSSION}

We began our studies by carrying out experiments aimed at optimizing the reaction conditions for oxidative furan fragmentation. Using cyclohexane-fused furan 17a as a model substrate, we evaluated various iron and copper salts, solvents, and temperatures (Table S1, Supporting Information) in reactions to form butenolide 19a, which has a terminal olefin group. Photooxidation of 17a with singlet oxygen in $\mathrm{MeOH}$ gave hydroperoxide 18a in nearly quantitative yield, and optimization experiments revealed that subsequent hydroperoxide fragmentation in the presence of iron(II) lactate (1.2 equiv) and $\mathrm{Cu}(\mathrm{OAc})_{2}(1.2$ equiv) in $3: 1 \mathrm{DMSO} / \mathrm{H}_{2} \mathrm{O}$ at room temperature afforded desired product 19a in $91 \%$ isolated yield. With the optimized conditions in hand, we set out to examine the substrate scope of the reaction (Table 1). Cycloalkane-fused furans with various ring sizes (17b-e, $n=2,3,7$, and 10, respectively) delivered desired butenolides $19 \mathrm{~b}-\mathbf{e}$ in $69-83 \%$ yields. In addition, furans with a C2-alkyl or -hydroxyalkyl substituent $(\mathbf{1 7 f}-\mathbf{h})$ proved to be viable substrates, giving rise to $\mathbf{1 9 f}-\mathbf{h}$ in good yields. Menthofuran-derived substrates $\mathbf{1 7} \mathbf{i}-\mathbf{k}$, which have a C2-hydroxyethyl or -aryl group, afforded products bearing a remote isopropenyl group (19i-k). Substrates with a C3-hydroxyalkyl, -amidylalkyl, -phenyl, or -allyl group (17l-o) were also compatible with the reaction conditions. However, because of the low solubility of furans 17n and 17o in $\mathrm{MeOH}$, petroleum ether was used as a co-solvent. Gratifyingly, substrates with an endo- or exocyclic double bond or a free hydroxyl group on the cycloalkyl ring were also tolerated: $17 \mathbf{p}-\mathbf{r}$ and $17 \mathbf{s}$ gave dienes $19 \mathbf{p}-\mathbf{r}$ and allylic alcohol 19s, respectively.

It should be mentioned that in all the examples mentioned above, hydroperoxide fragmentation generated a primary alkyl radical, which in turn gave rise to a terminal olefin after being oxidized by $\mathrm{Cu}(\mathrm{OAc})_{2}$. Accordingly, in the reactions of substrates $17 \mathbf{t}-\mathbf{v}$, radical fragmentation of the corresponding hydroperoxides $(\mathbf{1 8 t}-\mathbf{v})$ could conceivably generate secondary or tertiary alkyl radicals, which could lead to a mixture of 
Table 1. Synthesis of butenolides with an appended remote olefin group ${ }^{a}$

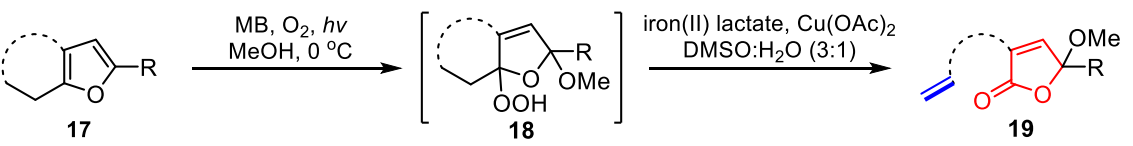

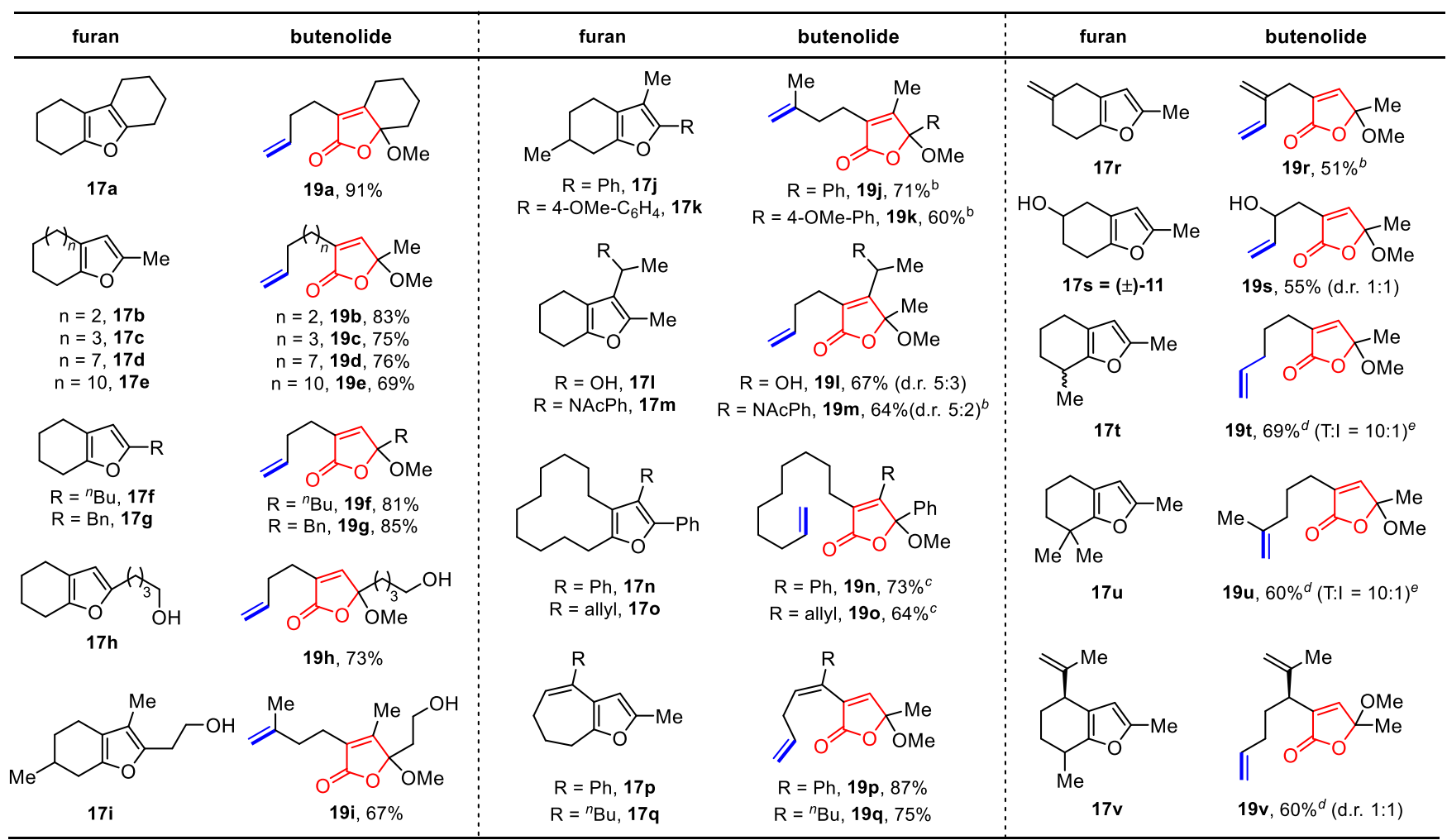

${ }^{a}$ Reaction conditions: $17(0.1-1 \mathrm{mmol}), \mathrm{MB}(1 \mathrm{~mol} \%), \mathrm{MeOH}, \mathrm{O}_{2}, h v, 0{ }^{\circ} \mathrm{C}, 30 \mathrm{~min}$, then iron(II) lactate (1.2 equiv), $\mathrm{Cu}(\mathrm{OAc})_{2}(1.2 \mathrm{equiv}), \mathrm{DMSO} / \mathrm{H}_{2} \mathrm{O}(3 / 1), \mathrm{rt}, 0.5 \mathrm{~h}$; Isolated yields are shown. ${ }^{b}$ iron(II) lactate (1.5 equiv), $\mathrm{Cu}(\mathrm{OAc})_{2}$ (1.5 equiv); ${ }^{c} \mathrm{MeOH} /$ petroleum ether (4/1) was used instead of MeOH; ${ }^{d}$ Iron(II) lactate (1.2 equiv), TEMPO (1.5 equiv), $\mathrm{MeOH}$, rt, $0.5 \mathrm{~h}$, then $\mathrm{DCB} / \mathrm{Pr}_{2} \mathrm{NH}(10: 1), 200{ }^{\circ} \mathrm{C}(\mathrm{MW}), 5 \mathrm{~h}$; ${ }^{e}$ Ratios of terminal olefin to internal olefin. Abbreviations: $\mathrm{MB}=\mathrm{methylene}$ blue, $\mathrm{DMSO}$ $=$ dimethylsulfoxide, $\mathrm{TEMPO}=$ 2,2,6,6-tetramethyl-1-piperidinyloxy, $\mathrm{DCB}=1,2$-dichlorobenzene.

terminal- and internal-olefin products after oxidation. Indeed, when these substrates were subjected to the standard conditions, a 2:1 to 4:1 mixture favoring the terminal-olefin products was obtained. Therefore, to increase the regioselectivity of these reactions, we used TEMPO (2,2,6,6-tetramethyl-1-piperidinyloxy) instead of $\mathrm{Cu}(\mathrm{OAc})_{2}$ to trap the alkyl radicals, which afforded butenolides with a remote TEMPO group. Subsequent removal of the TEMPO group ${ }^{24}$ by means of microwave heating gave desired products 19t-v in good yields with high regioselectivities. Notably, the use of this two-step procedure for dihydrocarvone-derived furan $17 \mathrm{v}$ yielded terminal olefin $19 \mathrm{v}$ as the sole product.

Compared with the species generated by ionic fragmentation, alkyl radical intermediates generated by radical fragmentation are more versatile, and they can be intercepted by a variety of functional groups, thereby providing rapid, divergent access to underexplored chemical space by means of radical functionalization. Having synthesized butenolides with an appended remote olefin group, we next turned our attention to trapping alkyl radical intermediate $\mathbf{2 1}$ (Table 2) with various radical coupling partners. This turned out to be nontrivial and necessitated considerable effort to optimize the reaction conditions. In general, either of two iron salts (iron(II) lactate or $\mathrm{FeSO}_{4}$ ) and one of three solvent systems $\left(\mathrm{MeOH}, \mathrm{DMSO} / \mathrm{H}_{2} \mathrm{O}\right.$ or $\left.\mathrm{CH}_{3} \mathrm{CN} / \mathrm{H}_{2} \mathrm{O}\right)$ provided the best results. Specifically, after photo-oxidation of 17a, addition of $\mathrm{FeSO}_{4}$ and $n$-dodecyl mercaptan (a hydrogen atom donor) led to the isolation of reduced butenolide $20 \mathbf{a}$ in $90 \%$ yield. Remarkably, this reaction was complete within $25 \mathrm{~s}$, as indicated by a color change (a photographic description is given on page S14 of Supporting Information). Gratifyingly, the use of $3: 1 \mathrm{DMSO} / \mathrm{D}_{2} \mathrm{O}^{25}$ resulted in selective deuteration at the terminal position, giving $\mathbf{2 0 b}$ in $72 \%$ yield with $88 \%$ deuterium incorporation. Given the documented importance of deuterium labeling in drug discovery, ${ }^{26}$ this reaction can be expected to be useful in the search for drug candidates with deuterated butenolide motifs.

Halogenation reactions proceeded smoothly to give chloride 20c, bromide 20d and iodide 20e in moderate to good yields. As expected, addition of TEMPO to the reaction mixture delivered $20 f$ in $79 \%$ yield. Interestingly, alkyl radical 21 could be intercepted by $\mathrm{O}_{2}$ to generate a mixture of aldehyde $\mathbf{2 0 g}$ and alcohol $20 \mathrm{~h}$ in the presence of $\mathrm{PhSiH}_{3}$. The aldehyde or the alcohol could be obtained selectively by subjecting the fragmentation reaction mixture to Dess-Martin oxidation conditions or to $\mathrm{NaBH}_{4}$ reduction conditions, respectively. In addition to $\mathrm{C}-$ $\mathrm{O}$ bond formation, $\mathrm{C}-\mathrm{S}$ and $\mathrm{C}-\mathrm{Se}$ bond formation could be accomplished by employing $\mathrm{Ph}_{2} \mathrm{~S}_{2}$ and $\mathrm{Ph}_{2} \mathrm{Se}_{2}$ as radical acceptors to obtain $20 \mathbf{i}$ and $\mathbf{2 0 j}$, respectively. We were pleased to find that we could introduce difluoromethylthio and trifluoromethylthio groups by trapping 21 with $\mathrm{PhSO}_{2} \mathrm{SCF}_{2} \mathrm{H}^{27}$ and $\mathrm{PhSO}_{2} \mathrm{SCF}_{3}{ }^{28}$ this transformation can be expected to find numerous applications in medicinal chemistry owing to the change of molecular lipophilicity induced by introduction of these groups. Furthermore, butenolides with a thiocyano group or an azide group $(20 \mathrm{~m}$ and 20n) were generated by reaction with freshly prepared $\mathrm{Cu}(\mathrm{SCN})_{2}$ and $\mathrm{Cu}\left(\mathrm{N}_{3}\right)_{2}{ }^{29}$ Alternatively, 20o could be 


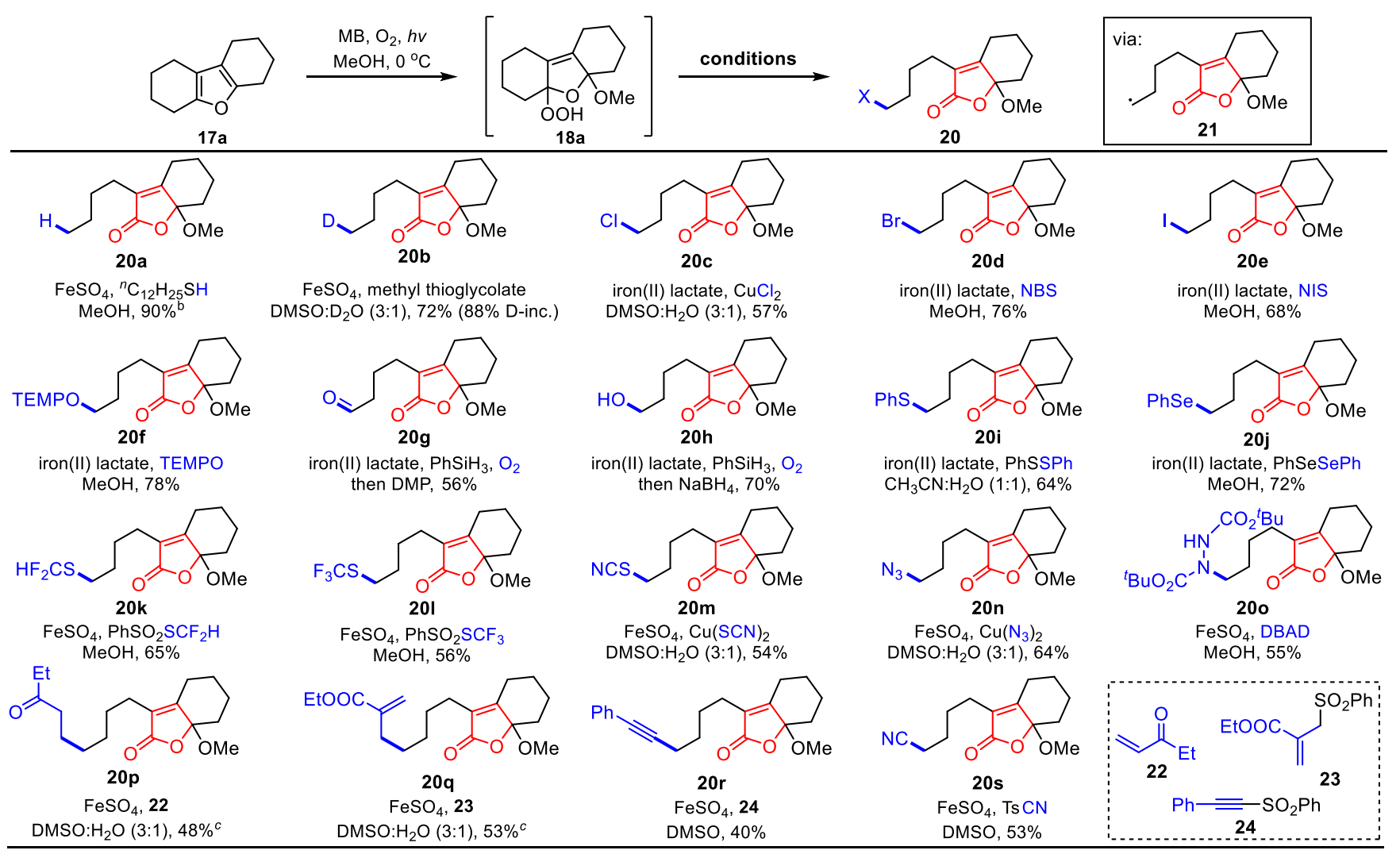

${ }^{a}$ Reaction conditions: $17 \mathrm{a}(0.1$ or $0.3 \mathrm{mmol}), \mathrm{MB}(1 \mathrm{~mol} \%), \mathrm{MeOH}, \mathrm{O}_{2}, h v, 0^{\circ} \mathrm{C}, 30 \mathrm{~min}$, then iron(II) salt $(1.2-2.5$ equiv), radical trapping reagent $(1.2-3 \mathrm{equiv})$, solvent, $\mathrm{rt}$, $0.5 \mathrm{~h}$; Isolated yields are shown. ${ }^{b}$ The reaction was completed in $25 \mathrm{~s}$ as indicated by a color change. ${ }^{c} \mathrm{Cu}(\mathrm{OAc})_{2}(1.5 \mathrm{equiv})$ and $\mathrm{LiOAc}(3$ equiv) were added. Abbreviations: NBS $=N$-bromosuccinimide, NIS $=N$-iodosuccinimide, DMP $=$ Dess-Martin periodinane, DBAD = di-tert-butyl azodicarboxylate, $T s=p$-toluenesulfonyl.

obtained via $\mathrm{C}-\mathrm{N}$ bond formation when di-tert-butyl azodicarboxylate was used as the acceptor.

Next, we evaluated the use of this radical fragmentationfunctionalization cascade for $\mathrm{C}-\mathrm{C}$ bond formation, which was much more difficult than carbon-heteroatom bond formation. For example, a Giese-type reaction with ethyl vinyl ketone $\mathbf{2 2}$ as the radical acceptor gave only a low yield (ca. 20\%) of desired product $20 \mathbf{p}$, along with major byproducts arising from oligomerization of the vinyl ketone. Extensive optimization studies revealed that using $\mathrm{Cu}(\mathrm{OAc})_{2}$ and $\mathrm{LiOAc}$ as additives and employing a reverse addition procedure (adding hydroperoxide to the reaction mixture) improved the yield of 20p to $48 \%$. Butenolide 20q, which has a remote acrylate ester group, was obtained in 53\% yield by reaction with $\mathbf{2 3}$ under the same conditions. Finally, radical alkynylation and cyanation proceeded in moderate yields when sulfone $\mathbf{2 4}$ and tosyl cyanide (commercially available), respectively, were used to trap the radical intermediate.

This oxidative furan fragmentation reaction provides facile, modular access to functionalized butenolides with various appended remote functional groups, including olefins, halides, aldehydes and azides. To demonstrate its broad utility for organic synthesis, we were interested in connecting these butenolides with other partners via fragment-coupling reactions (Scheme 1), aiming to: 1) further expand the chemical space of accessible butenolides; and 2) facilitate its application in natural product synthesis. Olefins are among the most versatile functional groups in organic chemistry, and we explored some of the numerous methods available for their diverse transformations. For example, an olefin cross-metathesis reaction ${ }^{30}$ between butenolide 19a and 22 in the presence of Hoveyda-Grubbs II catalyst furnished desired product $(E)-\mathbf{2 5}$ in $95 \%$ yield (Scheme 1a). Alternatively, 19a could react with 22 under Baran's reductive olefin-coupling conditions ${ }^{31}$ to give rise to $\mathbf{2 6}$ in $66 \%$ yield. A B-alkyl Suzuki-Miyaura cross-coupling reaction, ${ }^{32}$ a classic tool for total synthesis, between 19a and 27 afforded hydroarylated product $\mathbf{2 8}$ in $51 \%$ yield. We also carried out some transformations of bromo-substituted butenolide 22d. Although bromides are well-known to undergo $\mathrm{S}_{\mathrm{N}} 2$ substitution, pioneering work by $\mathrm{Fu}$ and co-workers demonstrated that they are also ideal electrophiles for a range of transition-metal-catalyzed cross-coupling reactions to form $\mathrm{C}-\mathrm{C}$ bonds. ${ }^{33} \mathrm{We}$ found that palladium-catalyzed Suzuki ${ }^{34}$ and Negishi ${ }^{35}$ cross-coupling reactions of 22d under Fu's conditions led to excellent yields of desired cross-coupling products $\mathbf{3 0}$ and 32, respectively (Scheme 1b).

Organoboron compounds, which can be easily accessed by means of olefin hydroboration, are versatile substrates for a wide array of transformations, including Suzuki coupling reactions, Zweifel olefination reactions, ${ }^{36}$ lithiation-borylation chemistry ${ }^{37}$ and conjunctive cross-coupling reactions. ${ }^{38}$ For instance, borate 33, which was synthesized via iridium-catalyzed hydroboration $^{39}$ of 19a, smoothly underwent Zweifel olefination to give two-carbon-extended olefin 34 in $71 \%$ yield (Scheme 1c). Sulfones are also valuable functionalities that can be used for Ramberg-Bäcklund reactions, Julia olefination reactions, and radical cross-coupling reactions. ${ }^{40} \mathrm{We}$ found that a Julia-Kocienski olefination reaction between 1-phenyl-1 $H$ - 


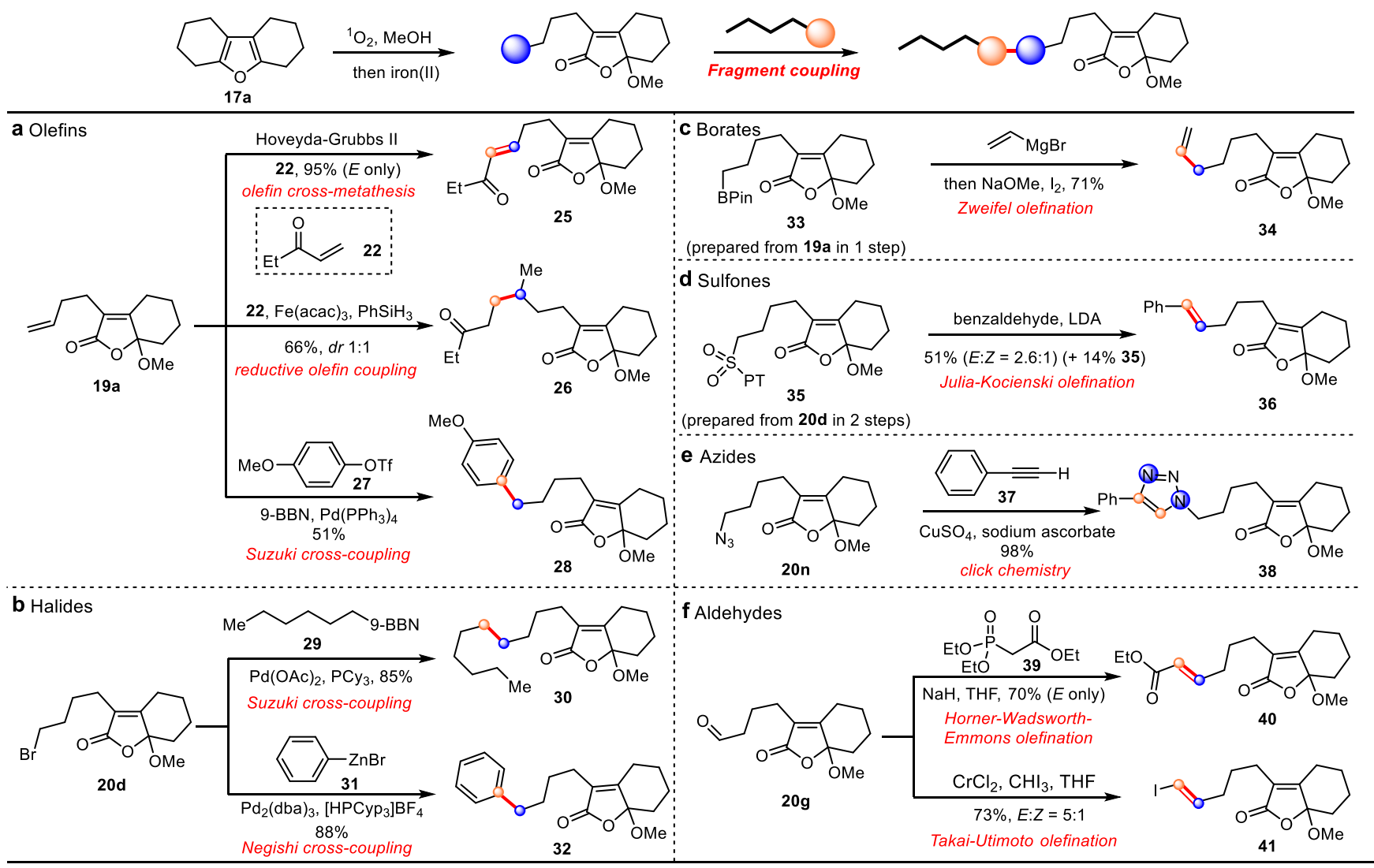

aYields of isolated products were shown. Abbreviations: acac $=$ acetylacetonyl, 9-BBN = 9-borabicyclo[3.3.1]nonane, Cy = cyclohexyl, dba $=$ dibenzylideneacetone, Cyp = cyclopentyl, PT = 1-phenyl-1H-tetrazol-5-yl, LDA = lithium diisopropylamide.

tetrazol-5-yl sulfone 35 (prepared from 20d in two steps) and benzaldehyde delivered olefin $\mathbf{3 6}$ in 51\% yield (Scheme 1d). Azides are widely used not only for generating amines but also for aza-Wittig reactions and click chemistry. ${ }^{41}$ Treatment of azide 20n with phenylacetylene in the presence of catalytic $\mathrm{CuSO}_{4}$ gave rise to 1,2,3-triazole $\mathbf{3 8}$ in excellent yield (Scheme 1e). ${ }^{42}$ Lastly, because aldehydes are known to be useful for generating $\mathrm{C}-\mathrm{C}$ bonds via nucleophilic addition reactions, olefination reactions, and so on, we subjected aldehyde $20 \mathrm{~g}$ to HornerWadsworth-Emmons olefination conditions and TakaiUtimoto olefination conditions and obtained good yields of desired unsaturated ester $\mathbf{4 0}$ and vinyl iodide 41, respectively (Scheme 1f).

To further illustrate the power of this new transformation, we present eight examples in which its use simplified the synthesis of a natural product (44) or known building blocks for natural products $(\mathbf{1 2}-\mathbf{1 6}, \mathbf{5 9}, \mathbf{6 3})$ (Scheme 2; detailed comparisons with prior work are provided in Figure S1 of Supporting Information). The first synthetic target was gorgonian lipid $\mathbf{4 4}$, which belongs to a class of anti-inflammatory fatty acid $\gamma$-hydroxybutenolides. ${ }^{43}$ The reported five-step procedure for its synthesis involves alkylation of a lithiated silyloxyfuran as the key step. In contrast, our synthesis commenced with an oxidative fragmentation reaction of known furan 17d (Scheme 2a). Addition of $N$-iodosuccinimide to the reaction mixture afforded butenolide $\mathbf{4 2}$, which has a terminal iodide. Copper-catalyzed alkyl-alkyl cross-coupling ${ }^{44}$ followed by in situ hydrolysis furnished $\mathbf{4 4}$ in $44 \%$ yield, thus completing its synthesis in only two steps from $\mathbf{1 7 d}$.
Next, we turned our attention to the annonaceous acetogenins, a large family of polyketide natural products found in Annonaceae species, with more than 400 family members having been isolated so far. ${ }^{45}$ Structurally, these compounds are characterized by an unbranched 32- or 34-carbon chain bearing some oxygenated functional groups (e.g., hydroxyl, ketone, epoxide, tetrahydrofuran, tetrahydropyran) and a terminal $\gamma$-butenolide. Annonaceous acetogenins exhibit a wide array of biological activities, including antiparasitic, pesticidal, antifeedant, antimicrobial, immunosuppressive and antitumor activities, and have therefore attracted substantial attention from the chemistry community. ${ }^{46}$ Although considerable progress has been made in the synthesis of the butenolide fragments, the reported routes generally suffer from being long and inefficient, and they lack modularity. For example, structurally similar butenolides 1216 (Scheme $2 b-d$ ), which are known synthetic intermediates of acetogenins pyranicin (4), ${ }^{3 \mathrm{f}}$ 10-hydroxyasimicin $(\mathbf{6 8}),{ }^{47}$ muricatetrocin $\mathrm{C}(\mathbf{6 7}),{ }^{6 \mathrm{a}}$ mucocin $(\mathbf{6 6})^{48}$ and asimicin $(\mathbf{6 9}){ }^{7 \mathrm{a}}$ respectively, were previously prepared in 10-16 steps from four distinct starting materials via four completely different sequences (see Supporting Information for details). In sharp contrast, the protocol we have described herein enabled concise, divergent and modular syntheses of all five of these intermediates from a single starting material (furan 11) and more importantly, via a single strategy: oxidative furan fragmentation (as shown in Tables 1 and 2) followed by fragment coupling (as shown in Scheme 1).

Our syntheses started with the preparation of chiral furan $\mathbf{1 1}$ via cyclization of known alkynyl ketone $\mathbf{4 5}$, followed by Noyori reduction (93\% ee) (Scheme $2 b$ ). After protection of the 

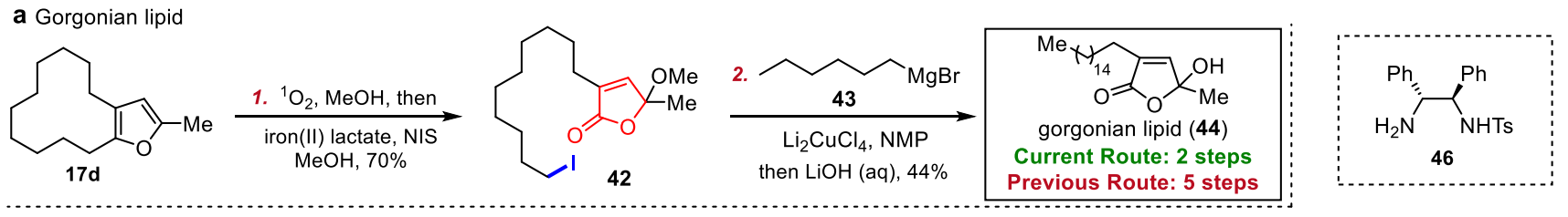

b Pyranicin fragment

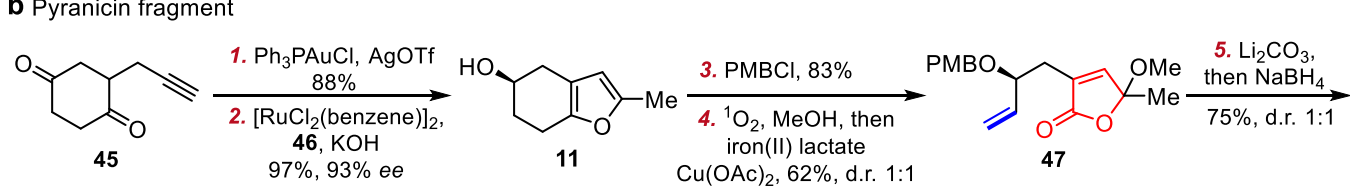

C Mucocin, muricatetrocin $\mathrm{C}$ and 10 -hydroxyasimicin fragments

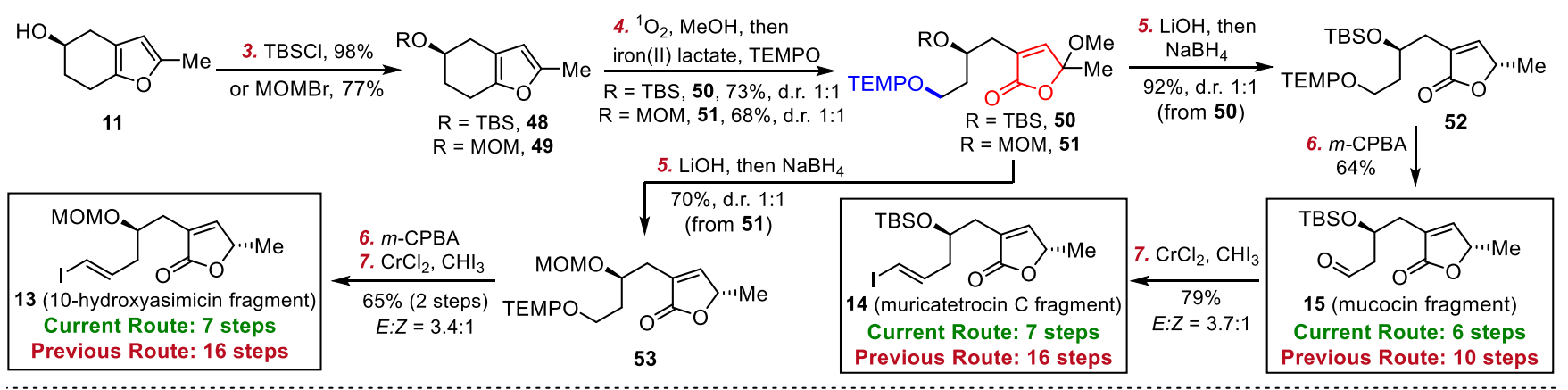

d Asimicin fragment

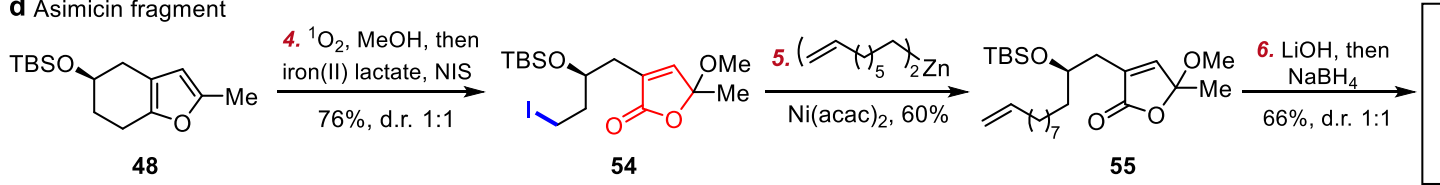

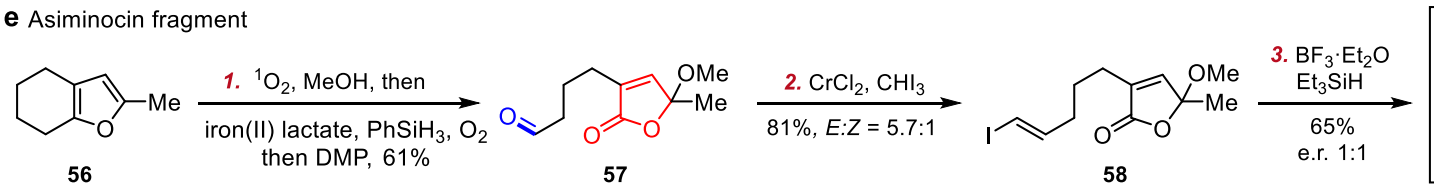

f Clavilactone A fragment

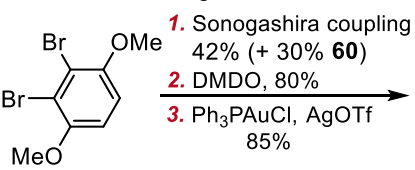

60

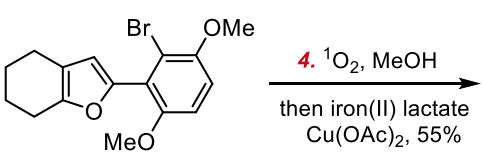

61

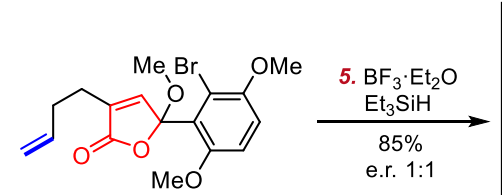

62

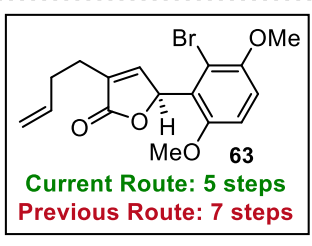

g Stereoselective ketal reduction

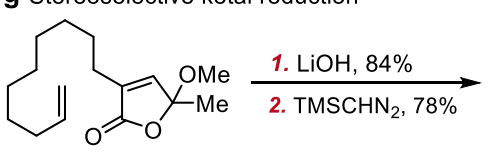

$19 d$

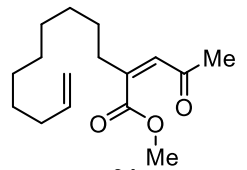

$64^{\mathrm{Me}}$

\section{3. (S)-Bu-CBS catecholborane \\ $94 \%, 88 \%$ ee}

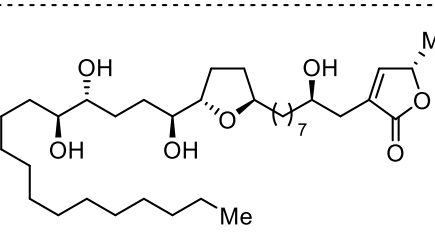

muricatetrocin $\mathrm{C}(67)$

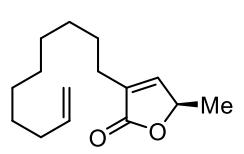

65

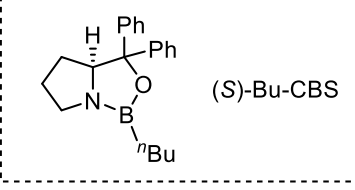

h Structures of annonaceous acetogenins $\mathrm{Me}$

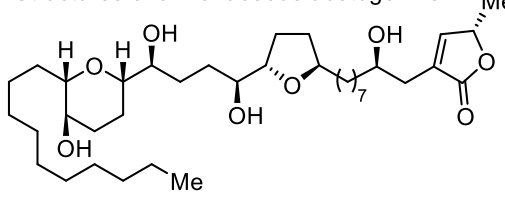

mucocin (66)
Me
$\mathrm{Me}$

${ }^{a}$ Yields of isolated products were shown. Abbreviations: NMP $=N$-methyl-2-pyrrolidinone, $\mathrm{PMB}=$ para-methoxybenzyl, TBS $=$ tert-butyldimethylsilyl, $\mathrm{MOM}=$ methoxymethyl, $m$-CPBA = meta-chloroperbenzoic acid, $\mathrm{DMDO}=$ dimethyl dioxirane, $\mathrm{CBS}=$ Corey-Bakshi-Shibata reagent .

hydroxyl group with a PMB group, reaction under our standard conditions delivered desired olefinic butenolide 47 in $62 \%$ yield.
Basic hydrolysis and subsequent reduction produced 12 in $75 \%$ yield. Alternatively, protection of the hydroxyl group of $\mathbf{1 1}$ with 
a TBS group, followed by oxidative furan fragmentation (iron(II)lactate, TEMPO) and basic reduction, delivered a diastereomeric mixture of butenolide $\mathbf{5 2}$ (Scheme 2c). Subsequent removal of TEMPO by $m$-CPBA afforded desired aldehyde $\mathbf{1 5}$, which was subjected to Takai olefination to give vinyl iodide $\mathbf{1 4}$ in $79 \%$ yield. If the hydroxyl group of $\mathbf{1 1}$ was protected with a MOM group instead of a TBS group, vinyl iodide $\mathbf{1 3}$ could be easily obtained via the same sequence. Moreover, butenolide 16, which has a long terminal-olefin side chain, could be accessed from furan $\mathbf{4 8}$ in three steps via oxidative fragmentation (iron(II) lactate, $N$-iodosuccinimide), nickel-catalyzed alkyl-alkyl cross-coupling (under Knochel's conditions) ${ }^{49}$ and subsequent reduction (Scheme 2d). In a similar manner, vinyl iodide 59, a known synthetic intermediate of asiminocin $\mathbf{7 0}^{5 \mathrm{a}}$, could be prepared via oxidative fragmentation, Takai olefination and reduction in three steps from known furan $\mathbf{5 6}$ (Scheme 2e). Notably, the previously reported approach to $\mathbf{5 9}$ required eight steps.

Finally, we prepared compound $\mathbf{6 3}$, an intermediate in the synthesis of clavilactone A (3), which belongs to a family of natural products with antifungal and antibacterial activities, as well as potent inhibitory activities against Ret/ptc1 and epidermal growth factor receptor tyrosine kinases (Scheme $2 \mathrm{f}$ ). ${ }^{2 \mathrm{~d}}$ The previous approach to 63 required seven steps, with a relay ringclosing metathesis reaction as the key step. Our synthetic sequence commenced with the preparation of C2-aryl furan $\mathbf{6 1}$ by means of Sonogashira coupling, epoxidation and Au-catalyzed cyclization. Furan $\mathbf{6 1}$ was subjected to the standard fragmentation condition and then ketal reduction, which furnished $\mathbf{6 3}$ in five steps from commercially available $\mathbf{6 0}$.

It should be pointed out that one unsolved problem with the above-described syntheses is the nonstereoselective reduction of the ketal moiety, which led to a diastereomeric mixture of the butenolide product. To provide a proof-of-principle solution to this problem, we used ketal 19d as a model substrate and converted it to $\gamma$-ketoester $\mathbf{6 4}$ in two steps. Gratifyingly, subsequent Corey-Bakshi-Shibata reduction ${ }^{50}$ of $\mathbf{6 4}$ gave rise to butenolide $\mathbf{6 5}$ in good yield with good enantioselectivity (Scheme $2 \mathrm{~g}$ ).

\section{- CONCLUSIONS}

In summary, we have developed a practical and efficient strategy to access underexplored functionalized butenolides from readily accessible furans via photo-oxidation with singlet oxygen and subsequent iron(II)-mediated radical fragmentation. The key aspects of this strategy are as follows: 1) it features mild reaction conditions, inexpensive reagents and operational simplicity; 2) it allows for precise and divergent installation of remote functional groups (such as olefins, halides, aldehydes, alcohols and azides) at a position distal to the butenolide moiety; 3) it has a broad substrate scope and generates diverse products; and 4) it has great potential to simplify retrosynthetic analysis. We have illustrated that readily available furans, which have traditionally been employed as surrogates for a number of fourcarbon building blocks, can undergo selective fragmentation to deliver valuable building blocks that are otherwise difficult or tedious to prepare. Moreover, we have shown that a variety of butenolides with diverse structural features can be expediently synthesized by means of a modular strategy involving oxidative furan fragmentation and subsequent cross-coupling reactions.

\section{ASSOCIATED CONTENT}

The Supporting Information is available free of charge on the ACS Publications website.
Experimental procedures, NMR spectra for all new compounds (PDF)

\section{AUTHOR INFORMATION}

\section{Corresponding Author}

* guijh@sioc.ac.cn

\section{Author Contributions}

$\uparrow$ These authors (J. B. and H. T.) contributed equally to this work. Notes

The authors declare no competing financial interest.

\section{ACKNOWLEDGMENT}

This paper is dedicated to Prof. Li-Xin Dai on the occasion of his 95th birthday. Financial support was provided by the "Thousand Youth Talents Plan", the Strategic Priority Research Program of the Chinese Academy of Sciences (Grant No. XDB20000000), the "Shanghai Rising-Star Plan" (Grant No. 17QA1405100), CAS Key Laboratory of Synthetic Chemistry of Natural Substances, and Shanghai Institute of Organic Chemistry. We thank Prof. Qilong Shen (SIOC) for providing $\mathrm{PhSO}_{2} \mathrm{SCF}_{3}$ and $\mathrm{PhSO}_{2} \mathrm{SCF}_{2} \mathrm{H}$ and Prof. Liang Yin (SIOC) for providing access to chiral HPLC instrument.

\section{REFERENCES}

(1) (a) Flematti, G. R.; Ghisalberti, E. L.; Dixon, K. W.; Trengove, R. D. A compound from smoke that promotes seed germination. Science 2004, 305, 977-977. (b) Jain, N.; Kulkarni, M. G.; Johannes, S. v. A butenolide, isolated from smoke, can overcome the detrimental effects of extreme temperatures during tomato seed germination. Plant Growth Regul. 2006, 49, 263-267. (c) Stevens, J. C.; Merritt, D. J.; Flematti, G. R.; Ghisalberti, E. L.; Dixon, K. W. Seed germination of agricultural weeds is promoted by the butenolide 3-methyl- $2 \mathrm{H}$-furo[2,3-c]pyran-2one under laboratory and field conditions. Plant Soil 2007, 298, 113124.

(2) (a) Cassinelli, G.; Lanzi, C.; Pensa, T.; Gambetta, R. A.; Nasini, G.; Cuccuru, G.; Cassinis, M.; Pratesi, G.; Polizzi, D.; Tortoreto, M.; Zunino, F. Clavilactones, a novel class of tyrosine kinase inhibitors of fungal origin. Biochem. Pharmacol. 2000, 59, 1539-1547. For synthetic studies, see: (b) Larrosa, I.; Da Silva, M. I.; Gómez, P. M.; Hannen, P.; Ko, E.; Lenger, S. R.; Linke, S. R.; White, A. J. P.; Wilton, D.; Barrett, A. G. M. Highly convergent three component benzyne coupling: The total synthesis of ent-clavilactone B. J. Am. Chem. Soc. 2006, 128, 14042-14043. (c) Yasui, H.; Yamamoto, S.; Takao, K.-i.; Tadano, K.-i. Synthetic studies toward clavilactone A: A concise access to $\alpha, \gamma$-substituted $\gamma$-butenolides by metathesis. Heterocycles 2006, 70, 135-141. (d) Takao, K.-i.; Nanamiya, R.; Fukushima, Y.; Namba, A.; Yoshida, K.; Tadano, K.-i. Total synthesis of (+)-clavilactone A and (-)-clavilactone B by ring-opening/ring-closing metathesis. Org. Lett. 2013, 15, 5582-5585. (e) Lv, L.; Shen, B.; Li, Z. Total synthesis of ( \pm )-clavilactones A, B, and proposed D through iron-catalyzed carbonylation-peroxidation of olefin. Angew. Chem. Int. Ed. 2014, 53, 4164-4167. (f) Suizu, H.; Shigeoka, D.; Aoyama, H.; Yoshimitsu, T. Total Synthesis of Clavilactone B: A Radical Cyclization Fragmentation Strategy. Org. Lett. 2015, 17, 126-129. (g) Takao, K.-i.; Mori, K.; Kasuga, K.; Nanamiya, R.; Namba, A.; Fukushima, Y.; Nemoto, R.; Mogi, T.; Yasui, H.; Ogura, A.; Yoshida, K.; Tadano, K.-i. Total Synthesis of Clavilactones. J. Org. Chem. 2018, 83, 7060-7075.

(3) (a) Alali, F. Q.; Rogers, L.; Zhang, Y.; McLaughlin, J. L. Unusual bioactive annonaceous acetogenins from Goniothalamus giganteus. Tetrahedron 1998, 54, 5833-5844. For synthetic studies, see: (b) Takahashi, S.; Kubota, A.; Nakata, T. Total synthesis of a cytotoxic acetogenin, pyranicin. Org. Lett. 2003, 5, 1353-1356. (c) Strand, D.; Rein, T. Total synthesis of pyranicin. Org. Lett. 2005, 7, 199-202. (d) Griggs, N. D.; Phillips, A. J. A concise and modular synthesis of pyranicin. Org. Lett. 2008, 10, 4955-4957. (e) Hattori, Y.; Furuhata, S.i.; Okajima, M.; Konno, H.; Abe, M.; Miyoshi, H.; Goto, T.; Makabe, H. Synthesis of pyranicin and its inhibitory action with bovine heart 
mitochondrial complex I. Org. Lett. 2008, 10, 717-720. (f) Crimmins, M. T.; Jacobs, D. L. Asymmetric total synthesis of pyranicin. Org. Lett. 2009, 11, 2695-2698.

(4) (a) Knight, D. W. Synthetic approaches to butenolides. Contemp. Org. Syn. 1994, 1, 287-315. (b) Barbosa, L. C. A.; Teixeirab, R. R.; Amarantec, G. W. Synthetic strategies for the preparation of butenolides and their transformation into other derivatives. Curr. Org. Syn. 2015, 12, 746-771. (c) Mao, B.; Fananas-Mastral, M.; Feringa, B. L. Catalytic asymmetric synthesis of butenolides and butyrolactones. Chem. Rev. 2017, 117, 10502-10566.

(5) For selected examples, see: (a) Marshall, J. A.; Piettre, A.; Paige, M. A.; Valeriote, F. A modular synthesis of annonaceous acetogenins. J. Org. Chem. 2003, 68, 1771-1779. (b) Han, H.; Sinha, M. K.; D'Souza, L. J.; Keinan, E.; Sinha, S. C. Total synthesis of 34-hydroxyasimicin and its photoactive derivative for affinity labeling of the mitochondrial complex I. Chem. Eur. J. 2004, 10, 2149-2158. (c) Donohoe, T. J.; Harris, R. M.; Burrows, J.; Parker, J. Total synthesis of (+)-cis-sylvaticin: Double oxidative cyclization reactions catalyzed by osmium. J. Am. Chem. Soc. 2006, 128, 13704-13705.

(6) For selected examples, see: (a) Dixon, D. J.; Ley, S. V.; Reynolds, D. J. The total synthesis of the annonaceous acetogenin, muricatetrocin C. Angew. Chem. Int. Ed. 2000, 39, 3622-3626. (b) Sinha, S. C.; Sinha, A.; Sinha, S. C.; Keinan, E. Tandem oxidative cyclization with rhenium oxide. Total synthesis of 17,18-bisepi-goniocin. J. Am. Chem. Soc. 1997, 119, 12014-12015. (c) Shiina, J.; Obata, R.; Tomoda, H.; Nishiyama, S. Synthesis of chiloscyphones and the biological activities of their synthetic intermediates against methicillin-resistant Staphylococcus aureus (MRSA). Eur. J. Org. Chem. 2006, 2006, 2362-2370. (d) Strand, D.; Norrby, P.-O.; Rein, T. Divergence en route to nonclassical annonaceous acetogenins. Synthesis of pyranicin and pyragonicin. J. Org. Chem. 2006, 71, 1879-1891.

(7) For selected examples, see: (a) Marshall, J. A.; Sabatini, J. J. An outside-in approach to adjacent bistetrahydrofuran annonaceous acetogenins with $\mathrm{C} 2$ core symmetry. Total synthesis of asimicin and a C32 analogue. Org. Lett. 2006, 8, 3557-3560. (b) Cowell, A.; Stille, J. K. Synthesis of lactones by the palladium-catalyzed carbonylation of halo alcohols. J. Am. Chem. Soc. 1980, 102, 4193-4198. (c) Crisp, G. T.; Meyer, A. G. Palladium-catalyzed, carbonylative, intramolecular coupling of hydroxyvinyl triflates. Synthesis of substituted $\alpha, \beta$-butenolides J. Org. Chem. 1992, 57, 6972-6975. (d) Hoye, T. R.; Ye, Z. Highly efficient synthesis of the potent antitumor annonaceous acetogenin (+)parviflorin. J. Am. Chem. Soc. 1996, 118, 1801-1802. (e) Liao, B.; Negishi, E.-i. Development of a method for the synthesis of $\alpha$-substituted $\alpha, \beta$-unsaturated lactones based on Stille-type Pd-catalyzed carbonylation of $(Z)$ - $\omega$-iodoalkenols. An efficient and selective synthesis of (+)-hamabiwalactone B. Heterocycles 2000, 52, 1241-1249.

(8) (a) Drahl, M. A.; Manpadi, M.; Williams, L. J. C-C fragmentation: origins and recent applications. Angew. Chem. Int. Ed. 2013, 52, 11222-11251. (b) Hoang, T. T.; Dudley, G. B.; Williams, L. J., Fragmentation reactions. In Comprehensive Organic Synthesis II (Second Edition), Knochel, P., Ed. Elsevier: Amsterdam, 2014; pp 842-860.

(9) For selected examples, see: (a) Maimone, T. J.; Shi, J.; Ashida, S.; Baran, P. S. Total synthesis of vinigrol. J. Am. Chem. Soc. 2009, 131, 17066-17067. (b) Winkler, J. D.; Rouse, M. B.; Greaney, M. F.; Harrison, S. J.; Jeon, Y. T. The first total synthesis of ( \pm )-ingenol. J. Am. Chem. Soc. 2002, 124, 9726-9728. (c) Mander, L. N.; McLachlan, M. M. The total synthesis of the galbulimima alkaloid GB 13. J. Am. Chem. Soc. 2003, 125, 2400-2401. (d) Ishikawa, H.; Colby, D. A.; Seto, S.; Va, P.; Tam, A.; Kakei, H.; Rayl, T. J.; Hwang, I.; Boger, D. L. Total synthesis of vinblastine, vincristine, related natural products, and key structural analogues. J. Am. Chem. Soc. 2009, 131, 4904-4916. (e) Nakajima, R.; Ogino, T.; Yokoshima, S.; Fukuyama, T. Total synthesis of (-)-mersicarpine. J. Am. Chem. Soc. 2010, 132, 1236-. (f) Hu, X.; Maimone, T. J. Four-step synthesis of the antimalarial cardamom peroxide via an oxygen stitching strategy. J. Am. Chem. Soc. 2014, 136, 5287-5290. (g) Koshimizu, M.; Nagatomo, M.; Inoue, M. Unified total synthesis of 3-epi-ryanodol, cinnzeylanol, cinncassiols A and B, and structural revision of natural ryanodol and cinnacasol. Angew. Chem. Int. Ed. 2016, 55, 2493-2497. (h) Zhao, X.-H.; Zhang, Q.; Du, J.-Y.;
Lu, X.-Y.; Cao, Y.-X.; Deng, Y.-H.; Fan, C.-A. Total synthesis of ( \pm )lycojaponicumin $\mathrm{D}$ and lycodoline-type lycopodium alkaloids. J. Am. Chem. Soc. 2017, 139, 7095-7103.

(10) Chen, Z.; Mercer, J. A. M.; Zhu, X.; Romaniuk, J. A. H.; Pfattner, R.; Cegelski, L.; Martinez, T. J.; Burns, N. Z.; Xia, Y. Mechanochemical unzipping of insulating polyladderene to semiconducting polyacetylene. Science 2017, 357, 475-479.

(11) For selected examples, see: (a) Roque, J. B.; Kuroda, Y.; Göttemann, L. T.; Sarpong, R. Deconstructive diversification of cyclic amines. Nature 2018, 564, 244-248. (b) Roque, J. B.; Kuroda, Y.; Göttemann, L. T.; Sarpong, R. Deconstructive fluorination of cyclic amines by carbon-carbon cleavage. Science 2018, 361, 171-174. (c) Smaligo, A. J.; Swain, M.; Quintana, J. C.; Tan, M. F.; Kim, D. A.; Kwon, O. Hydrodealkenylative $\mathrm{C}\left(\mathrm{sp}^{3}\right)-\mathrm{C}\left(\mathrm{sp}^{2}\right)$ bond fragmentation. Science 2019, 364, 681-685. (d) Osberger, T. J.; Rogness, D. C.; Kohrt, J. T.; Stepan, A. F.; White, M. C. Oxidative diversification of amino acids and peptides by small-molecule iron catalysis. Nature 2016, 537, 214 219. (e) Kamijo, S.; Dudley, G. B. Tandem nucleophilic addition/fragmentation reactions and synthetic versatility of vinylogous acyl triflates. J. Am. Chem. Soc. 2006, 128, 6499-6507.

(12) (a) Grob, C. A.; Baumann, W. 1,4-Elimination reaction with simultaneous fragmentation. Helv. Chim. Acta 1955, 38, 594-610. (b) Prantz, K.; Mulzer, J. Synthetic applications of the carbonyl generating Grob fragmentation. Chem. Rev. 2010, 110, 3741-3766.

(13) Eschenmoser, A.; Felix, D.; Ohloff, G. New fragmentation reaction of $\alpha, \beta$-unsaturated carbonyls. Synthesis of exaltone and racmuscone from cyclododecanone. Helv. Chim. Acta 1967, 50, 708-713.

(14) (a) Grob, C. A.; Schiess, P. W. Heterolytic fragmentation. A class of organic reactions. Angew. Chem. Int. Ed. 1967, 6, 1-15. (b) Grob, C. A. Mechanisms and stereochemistry of heterolytic fragmentation. Angew. Chem. Int. Ed. 1969, 8, 535-546.

(15) (a) Wu, X.; Zhu, C. Recent advances in radical-mediated C-C bond fragmentation of non-strained molecules. Chin. J. Chem. 2019 , 37, 171-182. (b) Morcillo, S. P. Radical-promoted C-C bond cleavage: a deconstructive approach for selective functionalization. Angew. Chem. Int. Ed. 2019, 58, doi: 10.1002/anie.201905218.

(16) De La Mare, H. E.; Kochi, J. K.; Rust, F. F. The oxidation of free radicals by metal ions. J. Am. Chem. Soc. 1961, 83, 2013-2013.

(17) Schreiber, S. L. Fragmentation reactions of $\alpha$-alkoxy hydroperoxides and application to the synthesis of the macrolide $( \pm)$-recifeiolide. J. Am. Chem. Soc. 1980, 102, 6163-6165.

(18) Huang, D.; Schuppe, A. W.; Liang, M. Z.; Newhouse, T. R. Scalable procedure for the fragmentation of hydroperoxides mediated by copper and iron tetrafluoroborate salts. Org. Biomol. Chem. 2016, 14, $6197-6200$.

(19) For selected examples, see: (a) Velthuisen, E. J.; Danishefsky, S. J. Total synthesis of $(+)$-suaveolindole: establishment of its absolute configuration. J. Am. Chem. Soc. 2007, 129, 10640-10641. (b) Liffert, R.; Linden, A.; Gademann, K. Total synthesis of the sesquiterpenoid periconianone A based on a postulated biogenesis. J. Am. Chem. Soc. 2017, 139, 16096-16099. (c) Schuppe, A. W.; Huang, D.; Chen, Y.; Newhouse, T. R. Total synthesis of (-)-xylogranatopyridine B via a palladium-catalyzed oxidative stannylation of enones. J. Am. Chem. Soc. 2018, 140, 2062-2066.

(20) For selected examples, see: (a) Schreiber, S. L.; Liew, W. Iron/copper promoted fragmentation reactions of $\alpha$-alkoxy hydroperoxides. The conversion of octalins into fourteen-membered ring macrolides. J. Am. Chem. Soc. 1985, 107, 2980-2982. (b) Gui, J.; Wang, D.; Tian, W. Biomimetic synthesis of 5,6-dihydro-glaucogenin C: Construction of the disecopregnane skeleton by iron(II)-promoted fragmentation of an $\alpha$-alkoxy hydroperoxide. Angew. Chem. Int. Ed. 2011, 50, 7093-7096. (c) Manoni, F.; Rumo, C.; Li, L.; Harran, P. G. Unconventional fragment usage enables a concise total synthesis of (-)-callyspongiolide. J. Am. Chem. Soc. 2018, 140, 1280-1284.

(21) Merino, P. Oxidative cleavage of furans. Org. React. 2015, 87, 1256. 
(22) Deng, J.; Wu, J.; Tian, H.; Bao, J.; Shi, Y.; Tian, W.; Gui, J. Alkynes from furans: A general fragmentation method applied to the synthesis of the proposed structure of aglatomin B. Angew. Chem. Int. Ed. 2018, 57, 3617-3621.

(23) Montagnon, T.; Tofi, M.; Vassilikogiannakis, G. Using singlet oxygen to synthesize polyoxygenated natural products from furans. Acc. Chem. Res. 2008, 41, 1001-1011.

(24) Ananchenko, G. S.; Fischer, H. Decomposition of model alkoxyamines in simple and polymerizing systems. I. 2,2,6,6-tetramethylpiperidinyl- $N$-oxyl-based compounds. J. Polym. Sci., Part A: Polym. Chem. 2001, 39, 3604-3621.

(25) (a) Loh, Y. Y.; Nagao, K.; Hoover, A. J.; Hesk, D.; Rivera, N. R.; Colletti, S. L.; Davies, I. W.; MacMillan, D. W. C. Photoredox-catalyzed deuteration and tritiation of pharmaceutical compounds. Science 2017, 358, 1182-1187. (b) Soulard, V.; Villa, G.; Vollmar, D. P.; Renaud, P. Radical deuteration with $\mathrm{D}_{2} \mathrm{O}$ : catalysis and mechanistic insights. J. Am. Chem. Soc. 2018, 140, 155-158.

(26) Atzrodt, J.; Derdau, V.; Kerr, W. J.; Reid, M. Deuterium- and tritium-labelled compounds: applications in the life sciences. Angew. Chem. Int. Ed. 2018, 57, 1758-1784.

(27) Zhu, D.; Shao, X.; Hong, X.; Lu, L.; Shen, Q. $\mathrm{PhSO}_{2} \mathrm{SCF}_{2} \mathrm{H}$ : A shelf-stable, easily scalable reagent for radical difluoromethylthiolation. Angew. Chem. Int. Ed. 2016, 55, 15807-15811.

(28) Xu, B.; Wang, D.; Hu, Y.; Shen, Q. Silver-catalyzed ring-opening difluoromethylthiolation/trifluoromethylthiolation of cycloalkanols with $\mathrm{PhSO}_{2} \mathrm{SCF}_{2} \mathrm{H}$ or $\mathrm{PhSO}_{2} \mathrm{SCF}_{3}$. Org. Chem. Front. 2018, 5, 1462 1465.

(29) Čeković, Z. i.; Cvetković, M. Functionallization of the $\delta$-carbon atom by the ferrous ion induced decomposition of alkyl hydroperoxides in the presence of cupric salts. Tetrahedron Lett. 1982, 23, 3791-3794.

(30) Trnka, T. M.; Grubbs, R. H. The development of $\mathrm{L}_{2} \mathrm{X}_{2} \mathrm{Ru}=\mathrm{CHR}$ olefin metathesis catalysts: an organometallic success story. Acc. Chem. Res. 2001, 34, 18-29.

(31) Lo, J. C.; Yabe, Y.; Baran, P. S. A practical and catalytic reductive olefin coupling. J. Am. Chem. Soc. 2014, 136, 1304-1307.

(32) (a) Chemler, S. R.; Trauner, D.; Danishefsky, S. J. The B-alkyl Suzuki-Miyaura cross-coupling reaction: development, mechanistic study, and applications in natural product synthesis. Angew. Chem. Int. Ed. 2001, 40, 4544-4568. (b) Ohe, T.; Miyaura, N.; Suzuki, A. Palladium-catalyzed cross-coupling reaction of organoboron compounds with organic triflates. J. Org. Chem. 1993, 58, 2201-2208.

(33) Choi, J.; Fu, G. C. Transition metal-catalyzed alkyl-alkyl bond formation: Another dimension in cross-coupling chemistry. Science 2017, 356, eaaf7230

(34) Netherton, M. R.; Dai, C.; Neuschütz, K.; Fu, G. C. Room-temperature alkyl-alkyl Suzuki cross-coupling of alkyl bromides that possess $\beta$ hydrogens. J. Am. Chem. Soc. 2001, 123, 10099-10100.

(35) Zhou, J.; Fu, G. C. Palladium-catalyzed Negishi cross-coupling reactions of unactivated alkyl iodides, bromides, chlorides, and tosylates. J. Am. Chem. Soc. 2003, 125, 12527-12530.
(36) Zweifel, G.; Arzoumanian, H.; Whitney, C. C. A convenient stereoselective synthesis of substituted alkenes via hydroboration-iodination of alkynes. J. Am. Chem. Soc. 1967, 89, 3652-3653.

(37) Leonori, D.; Aggarwal, V. K. Lithiation-borylation methodology and its application in synthesis. Acc. Chem. Res. 2014, 47, 3174-3183.

(38) Zhang, L.; Lovinger, G. J.; Edelstein, E. K.; Szymaniak, A. A.; Chierchia, M. P.; Morken, J. P. Catalytic conjunctive cross-coupling enabled by metal-induced metallate rearrangement. Science 2016, 351, 70-74.

(39) Yamamoto, Y.; Fujikawa, R.; Umemoto, T.; Miyaura, N. Iridiumcatalyzed hydroboration of alkenes with pinacolborane. Tetrahedron 2004, 60, 10695-10700.

(40) Merchant, R. R.; Edwards, J. T.; Qin, T.; Kruszyk, M. M.; Bi, C.; Che, G.; Bao, D.-H.; Qiao, W.; Sun, L.; Collins, M. R.; Fadeyi, O. O.; Gallego, G. M.; Mousseau, J. J.; Nuhant, P.; Baran, P. S. Modular radical cross-coupling with sulfones enables access to $\mathrm{sp}^{3}$-rich (fluoro)alkylated scaffolds. Science 2018, 360, 75-80.

(41) Kolb, H. C.; Finn, M. G.; Sharpless, K. B. Click chemistry: Diverse chemical function from a few good reactions. Angew. Chem. Int. Ed. 2001, 40, 2004-2021.

(42) Himo, F.; Lovell, T.; Hilgraf, R.; Rostovtsev, V. V.; Noodleman, L.; Sharpless, K. B.; Fokin, V. V. Copper(I)-catalyzed synthesis of azoles. DFT study predicts unprecedented reactivity and intermediates. $J$. Am. Chem. Soc. 2005, 127, 210-216.

(43) Boukouvalas, J.; Loach, R. P. General, regiodefined access to $\alpha$ substituted butenolides through metal-halogen exchange of 3-bromo2 -silyloxyfurans. Efficient synthesis of an anti-inflammatory gorgonian lipid. J. Org. Chem. 2008, 73, 8109-8112.

(44) (a) Tamura, M.; Kochi, J. Coupling of Grignard reagents with organic halides. Synthesis 1971, 1971, 303-305. (b) Cahiez, G.; Chaboche, C.; Jézéquel, M. Cu-catalyzed alkylation of Grignard reagents: A new efficient procedure. Tetrahedron 2000, 56, 2733-2737.

(45) Bermejo, A.; Figadère, B.; Zafra-Polo, M.-C.; Barrachina, I.; Estornell, E.; Cortes, D. Acetogenins from annonaceae: recent progress in isolation, synthesis and mechanisms of action. Nat. Prod. Rep. 2005, 22, 269-303.

(46) Li, N.; Shi, Z.; Tang, Y.; Chen, J.; Li, X. Recent progress on the total synthesis of acetogenins from annonaceae. Beilstein J. Org. Chem. 2008, 4, doi:10.3762/bjoc.4.48.

(47) Nattrass, G. L.; Díez, E.; McLachlan, M. M.; Dixon, D. J.; Ley, $\mathrm{S}$. V. The total synthesis of the annonaceous acetogenin 10-hydroxyasimicin. Angew. Chem. Int. Ed. 2005, 44, 580-584.

(48) Bäurle, S.; Hoppen, S.; Koert, U. Total synthesis of (-)-mucocin. Angew. Chem. Int. Ed. 1999, 38, 1263-1266.

(49) Giovannini, R.; Stüdemann, T.; Dussin, G.; Knochel, P. An efficient nickel-catalyzed cross-coupling between $\mathrm{sp}^{3}$ carbon centers. Angew. Chem. Int. Ed. 1998, 37, 2387-2390.

(50) Corey, E. J.; Helal, C. J. Reduction of carbonyl compounds with chiral oxazaborolidine catalysts: A new paradigm for enantioselective catalysis and a powerful new synthetic method. Angew. Chem. Int. Ed. 1998, 37, 1986-2012. 


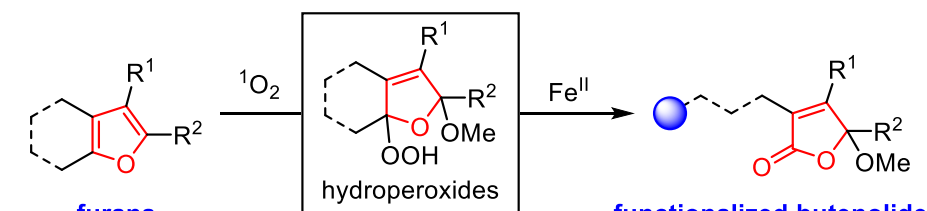

furans

hydroperoxides

functionalized butenolides

[ubiquitous] $Q$ olefin, halides, borate [biologically important]

[readily accessible] carbonyl, azide..

[synthetically challenging] 